\title{
Pengaruh Penggunaan Pendekatan Saintifik Berbasis Inkuiri terhadap Hasil Belajar Materi Pencemaran Lingkungan Siswa SMP Kelas VII Tahun Pelajaran 2019/2020
}

\author{
Maria Yasinta Kemba, Adrianus Nasar*, Yasinta Embu Ika \\ Pendidikan Fisika, Universitas Flores, Indonesia \\ *adrianus710@gmail.com
}

\begin{abstract}
Abstrak
Tujuan penelitian ini adalah untuk mengetahui pengaruh pendekatan saintifik berbasis inkuiri terhadap hasil belajar IPA materi pencemaran lingkungan siswa kelas VII SMP Negeri Sokoria Tahun Pelajaran 2019/2020. Jenis penelitian adalah ex-post facto menggunakan pendekatan deskriptif kuantitatif Populasi penelitian berjumlah 82 siswa dan sampel berjumlah 45 siswa yang diperoleh dengan teknik simple random sampling. Data penelitian ditampilkan secara deskriptif dan dianalisis dengan uji- $t$ satu sampel. Hasil penelitian menunjukkan bahwa pengaruh pendekatan saintifik berbasis inkuiri signifikan terhadap hasil belajar IPA materi pencemaran lingkungan di mana nilai $t_{\text {hitung }}$ sama dengan 27,328 dengan signifikan 0,000 kurang dari 0,05.
\end{abstract}

Kata kunci: hasil belajar, inkuiri, pendekatan saintifik.

Dikirim: 13 Agustus 2021

Direvisi: 16 September 2021

Diterima: 06 Oktober 2021

\section{Identitas Artikel:}

Kemba, M. Y., Nasar, A., \& Ika, Y. E. (2022). Pengaruh Penggunaan Pendekatan Saintifik Berbasis Inkuiri terhadap Hasil Belajar Materi Pencemaran Lingkungan Siswa SMP Kelas VII Tahun Pelajaran 2019/2020. Jurnal Ilmu Pendidikan (JIP) STKIP Kusuma Negara, 13(2), 9399.

\section{PENDAHULUAN}

Pendidikan merupakan faktor yang sangat penting bagi siswa dalam menjalani kehidupan. Melalui pendidikan siswa dapat mengembangkan kemampuan di dalam dirinya sesuai dengan ilmu pengetahuan yang telah diperoleh sehingga mampu menghadapi perkembangan dan perubahan yang terjadi di lingkungan sekitarnya. Hal ini sejalan dengan tujuan pendidikan nasional yaitu untuk berkembangnya potensi peserta didik agar memiliki yang berilmu, cakap, kreatif, kritis dan tanggung jawab (KEMENKUMHAM, 2002). Tujuan ini akan terwujud melalui proses yang terstruktur dan sistematis dalam lembaga pendidikan. Sekolah sebagai salah satu lembaga pendidikan yang diberikan tugas untuk mewujudkan tujuan pendidikan nasional harus menjalankan perannya dengan baik (Calam \& Qurniati, 2016). Sekolah menjadi tempat di mana seorang pendidik dapat mempengaruhi siswa untuk belajar melalui proses pembelajaran (Kholik, 2017).

Dalam kurikulum 2013 disebutkan bahwa proses pembelajaran diarahkan agar siswa mencari tahu melalui proses yang aktif dan konstruktif sehingga siswa akan dibiasakan untuk membangun pengetahuannya sendiri berdasarkan konteks nyata yang bermakna bagi dirinya (Pahrudin \& Pratiwi, 2019). Kemampuan siswa yang ingin diharapkan ini membutuhkan karakteristik pembelajaran menggunakan pendekatan saintifik (KEMENDIKBUD, 2016a) karena pendekatan scientific merupakan proses pembelajaran yang dirancang sedemikian rupa yang mana 
tujuannya agar peserta didik secara aktif mengonstruk konsep, hukum atau prinsip melalui beberapa tahapan seperti, mengamati (untuk mengidentifikasi atau menemukan masalah), merumuskan masalah, mengajukan atau merumuskan hipotesis, mengumpulkan data dengan berbagai teknik, menganalisis data, kemudian menarik kesimpulan serta mengomunikasikan konsep, hukum atau prinsip yang telah ditemukan (Sufairoh, 2016). Pendekatan ilmiah ini mencakup mengamati (observing), menanya (questioning), menalar (associating), mencoba (experimenting), membentuk jejaring (networking) untuk semua mata pelajaran (Sufairoh, 2016).

Pendekatan saintifik adalah pendekatan yang menggunakan langkah-langkan serta kaidah ilmiah dalam proses pembelajaran (Maradila \& Wahono, 2019). Langkah ilmiah yang diterapkan meliputi menemukan masalah, merumuskan masalah, mengajukan hipotesis, mengumpulkan data, menganalisis data, dan menarik kesimpulan (Musfiqon \& Nurdyansyah, 2015). Pendekatan saintifik dalam pembelajaran Ilmu Pengetahuan Alam (IPA) diarahkan pada upaya guru dalam bertindak agar siswa dapat mempelajari dan memahami hakikat IPA. Karakteristik pembelajaran IPA yang yang mendorong siswa dalam mempelajari dan memahami hakikat IPA adalah melalui aktivitas inkuiri. Aktivitas inkuiri dalam pembelajaran IPA mampu mengungkap hakikat IPA yaitu sebagai sikap, proses, dan produk (Sayekti, 2016). Gagasan dasar inkuri ini adalah pengetahuan, observasi, gagasan-gagasan, dan pertanyaan-paertanyaan (National Research Council, 1996).

Penggunaan aktivitas inkuiri pada materi Pencemaran lingkungan didasarkan pada kompetensi dasar (KD) yaitu menganalisis terjadinya pencemaran lingkungan dan dampaknya bagi ekosistem (KEMENDIKBUD, 2016b). Kemampuan menganalisis merupakan proses berpikir tingkat tinggi (high order thinking skill, HOTS) (Ariyana, Bestary \& Mohandas, 2018) dan merupakan ciri khas dari aktivitas inkuiri (Musfiqon \& Nurdyansyah, 2015). Lebih lanjut disebutkan, inkuiri merupakan kegiatan pembelajaran yang melibatkan secara maksimal seluruh kemampuan siswa untuk mencari dan menyelidiki sesuatu (benda, manusia atau peristiwa) secara sistematis, kritis, logis, analitis sehingga mereka dapat merumuskan sendiri penemuannya dengan penuh percaya diri (Musfiqon \& Nurdyansyah, 2015).

Permasalahan pembelajaran IPA di SMP Negeri Sokoria adalah pembelajaran belum maksimal dalam mendorong sikap keingin tahuan siswa, keterampilan mengamati siswa yang masih rendah, keterampilan berkomunikasi yang belum efektif, dan keterampilan menganalisis yang masih rendah. Tujuan penelitian ini adalah untuk mengetahui pengaruh pendekatan saintifik berbasis inkuiri terhadap hasil belajar IPA materi pencemaran lingkungan siswa kelas VII SMP Negeri Sokoria Tahun Pelajaran 2019/2020.

\section{METODE PENELITIAN}

Jenis penelitian yang digunakan adalah penelitian deskriptif kuantitatif. Desain penelitian adalah Ex-Post Facto. Penelitian Ex-Post Facto yaitu metode yang sering digunakan dan merupakan metode yang bermanfaat serta memberikan informasi penting bagi pengambilan keputusan dibidang pendidikan. Penelitian Ex-Post Facto akan meneliti hubungan apa yang menyebabkan sesuatu itu terjadi 
dan apa yang mengakibatkannya dan tidak dimanipulasi. Penelitian sebab-akibat dilakukan terhadap kegiatan yang telah berlangsung.

Populasi penelitian adalah kelas VII yang berjumlah 82 siswa. Banyaknya siswa yang dijadikan sampel dapat diperoleh dengan menggunakan penentuan yang dikemukakan oleh Isaac dan Michel (dalam Sugiyono, 2007) dengan tingkat kesalahan 5\%. Jumlah sampel penelitian berdasarkan ketentuan tersebut adalah sebesar 45 siswa. Jumlah siswa yang dijadikan sampel sebanyak 15 orang per kelas dan dilakukan secara acak yaitu memilih nama-nama siswa yang tertera dalam daftar nilai siswa pada masing-masing kelas.

Data hasil belajar ditampilkan dalam bentuk tabel dan grafik. Nilai siswa dikelompokkan dalam interval untuk mendeskripsikan predikat hasil belajar. Predikat hasil belajar mencakup sangat baik, baik, cukup baik, dan kurang baik (Ginting \& Permana, 2018). Interval untuk penentuan predikat dilakukan dengan rumus berikut.

$$
\text { Interval }=\frac{100-\mathrm{KKM}}{3}
$$

Berdasarkan rumus ini, maka rentangan nilai di atas Kriteria Ketuntasan Minimal $(\mathrm{KKM}=68)$ sebesar 10,6. Data deskriptif hasil belajar dan predikatnya mengikuti ketentuan berikut:

Tabel 1. Nilai dan Predikat Hasil Belajar

\begin{tabular}{ll}
\hline \multicolumn{1}{c}{ Nilai } & \multicolumn{1}{c}{ Predikat } \\
\hline $89,4-100$ & Sangat baik \\
$78,7-89,3$ & Baik \\
$68-78,6$ & Cukup baik \\
$<68$ & Kurang baik \\
\hline
\end{tabular}

Analisis data dilakukan secara deskriptif dan inferesial melalui uji- $t$ satu sampel (Ary dkk., 2018), dengan pembanding nilai KKM sebesar 68 mata pelajaran IPA di SMP Negeri Sokoria. Variabel yang berkaitan dengan uji-t satu sampel ini adalah nilai rata-rata, standar deviasi, dan jumlah sampel. Penghitungan uji- $t$ dilakukan dengan bantuan aplikasi Statistical Product and Service Solutions (SPSS) versi 21. Kriterianya adalah Jika Sig. $>\alpha$, maka $\mathrm{H}_{0}$ diterima dan Jika Sig. $<\alpha$, maka $\mathrm{H}_{0}$ ditolak (Rosana, 2016).

\section{HASIL PENELITIAN}

Data hasil belajar materi pencemaran lingkungan untuk 45 siswa ditunjukkan melalui Tabel 2.

Tabel 2. Data Deskriptif Hasil Belajar Siswa

\begin{tabular}{cccccc}
\hline $\begin{array}{c}\text { Nilai pencemaran } \\
\text { lingkungan }\end{array}$ & $\mathrm{N}$ & Min & Max & Mean & $\begin{array}{c}\text { Std. } \\
\text { Deviation }\end{array}$ \\
\cline { 2 - 6 } & 45 & 72 & 86 & 79.78 & 2.891 \\
\hline
\end{tabular}


Hasil belajar untuk 45 siswa berdasarkan Tabel 2 di atas menunjukkan bahwa nilai rerata sebesar 79,78 dengan standar deviasi 2,891. Nilai maksimum siswa adalah 86 dan nilai minimum adalah 72, hal ini menunjukkan bahwa hasil belajar siswa materi pencemaran lingkungan berada di atas nilai KKM.

Hasil belajar siswa dikonversikan ke dalam predikat pada Tabel 1 di atas tampak dalam Tabel 3.

Tabel 3. Nilai dan Predikat Hasil Belajar

\begin{tabular}{cccc}
\hline Nilai & Predikat & Jumlah Siswa & Persentase \\
\hline $89,4-100$ & Sangat baik & 0 & 0 \\
$78,7-89,3$ & Baik & 29 & 64 \\
$68-78,6$ & Cukup baik & 16 & 36 \\
$<68$ & Kurang baik & 0 & 0 \\
\hline \multicolumn{2}{c}{ Jumlah } & 45 & 100 \\
\hline
\end{tabular}

Data hasil belajar dan predikatnya ditampilkan dalam grafik pada Gambar 1 berikut.

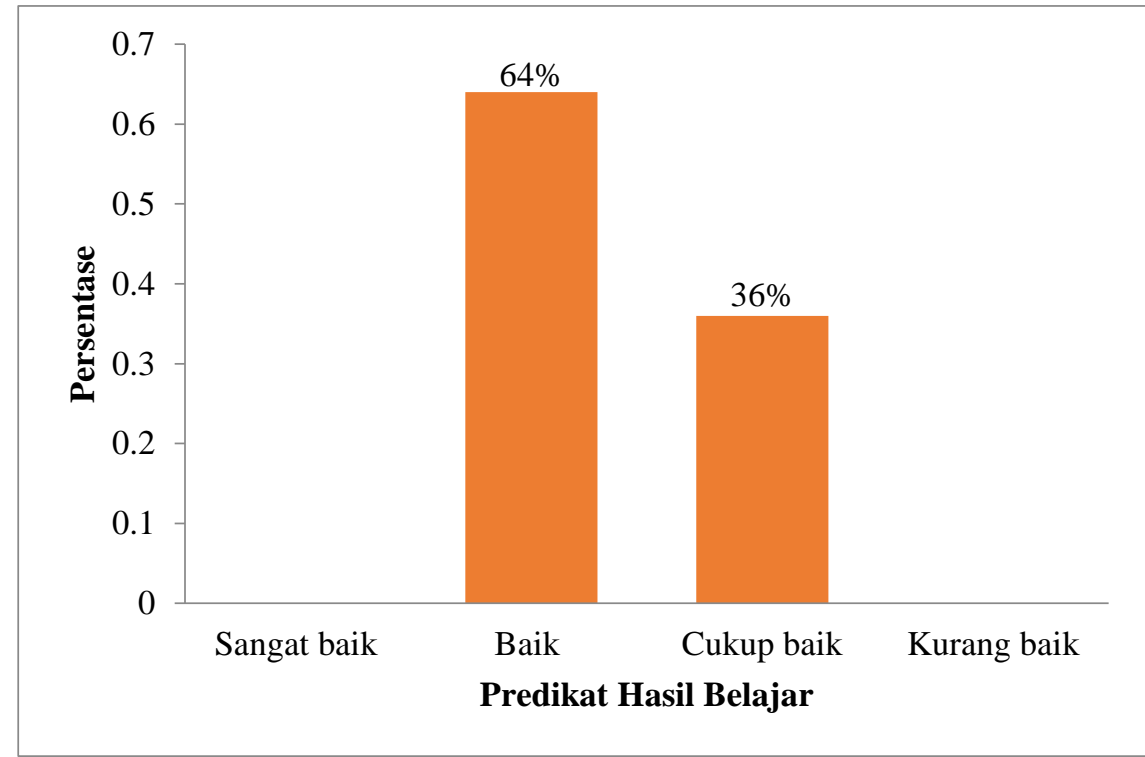

Gambar 1. Grafik Predikat Hasil Belajar

Berdasarkan data pada Tabel 3 dan Gambar 1 di atas, hasil belajar materi pencemaran lingkungan siswa kelas VII memiliki 64\% pada kategori baik dan $36 \%$ pada kategori cukup baik. Data ini menunjukkan bahwa nilai siswa SMP Negeri Sokoria berada di atas nilai KKM.

Pengaruh pendekatan saintifik terhadap hasil belajar diketahui melalui uji-t. Uji normalitas data digunakan sebagai syarat untuk dilakukannya uji-t satu sampel. Hasil uji normalitas data hasil belajar siswa pada materi pencemaran lingkungan menggunakan uji Kolmogorov Smirnov menunjukkan signifikan (Sig.=0,177) dan uji Shapiro-Wilk menunjukkan signifikan (Sig.=0,215). Hasil ini menunjukkan bahwa data hasil belajar siswa pada materi pencemaran lingkungan memenuhi syarat normalitas untuk uji-t satu sampel karena nilai signifikan lebih besar dari 0,05 . 
Pengujian hipotesis penelitian dilakukan melalui uji- $t$ satu sampel dengan perhitungan menggunakan bantuan aplikasi SPSS versi 21. Hasil perhitungan ditunjukkan pada Tabel 4.

Tabel 4. Uji Hipotesis Hasil Belajar

\begin{tabular}{ccccccc}
\hline & \multicolumn{6}{c}{ One-Sample Test } \\
\cline { 2 - 7 } Hasil Belajar & \multirow{2}{*}{$t$} & $d f$ & Sig. & Mean & \multicolumn{2}{c}{ 95\% CI } \\
\cline { 2 - 7 } & & & (2-tailed) & Difference & Lower & Upper \\
\cline { 2 - 7 } & 27.328 & 44 & .000 & 11.778 & 10.91 & 12.65 \\
\hline
\end{tabular}

Berdasarkan Tabel 4, hasil perhitungan uji-t dengan nilai rerata hasil belajar materi pencemaran 79,78, standar deviasi 2,891, nilai pembanding (KKM) 68 (test value) untuk sampel 45 siswa adalah $t=27,328$ dengan Sig. $=0,000<0,05=\alpha$. Hasil ini menunjukkan bahwa ada pengaruh penggunaan pendekatan saintifik berbasis inkuiri terhadap hasi belajar siswa materi pencemaran lingkungan.

\section{PEMBAHASAN}

Pendekatan saintifik berbasis inkuiri disarankan untuk digunakan dalam proses pembelajaran IPA di sekolah, karena pendekatan ini menjadi acuan untuk dapat mempelajarari IPA sebagai sikap, proses, dan produk. Proses pembelajaran IPA materi pencemaran lingkungan disarankan menggunakan pendekatan ini karena kompetensi yang dianjurkan berada pada kemampuan berpikir tingkat tinggi yaitu pada kemampuan menganalisis. Kemampuan menganalisis merupakan keterampilan abstrak di mana seseorang dapat menstruktur informasi informasi ke dalam bagian yang lebih kecil untuk mengenali pola atau hubungannya, dan mampu mengenali serta membedakan faktor penyebab dan akibat dari sebuah scenario yang rumit.

Berdasarkan hasil penelitian menunjukkan bahwa hasil belajar siswa melampaui nilai KKM IPA (68) di mana nilai minimum siswa sebesar 72 dan maksimum 86. Hasil belajar ini menggambarkan bahwa ada pengaruh pendekatan saintifik berbasis inkuiri terhadap hasil belajar IPA materi pencemaran lingkingan. Hasil ini setara dengan hasil penelitian yang dikemukakan Suseno yaitu penerapan model inquiry learning dengan pendekatan saintifik dapat meningkatkan keterampilan abstrak dan prestasi belajar siswa (Suseno, 2016). Hasil penelitian lain juga menunjukkan pendekatan saintifik metode inquiri dapat meningkatkan hasil belajar (Handriani, Harjono \& Doyan, 2017).

Pengaruh pendekatan saintifik berbasis inkuiri terhadap hasil belajar pada pengujian menggunakan uji- $t$ menunjukkan bahwa pendekatan ini berpengaruh terhadap hasil belajar IPA siswa. Hasil penelitian ini didukung oleh penelitian laian yaitu terdapat pengaruh yang signifikan penggunaan model inkuiri terbimbing dengan pendekatan saintifik terhadap hasil belajar siswa yang ditunjukkan dengan $t_{\text {hitung }}=2,444>t_{\text {tabel }}=2,004$. Hasil penelitian lain juga menunjukkan penerapan pendekatan saintifik berbasis model pembelajaran inkuiri dapat meningkatkan keaktifan dan penguasaan kompetensi pengetahuan IPA siswa. 


\section{SIMPULAN}

Hasil penelitian menunjukkan bahwa ada pengaruh pendekatan saintifik berbasis inkuiri dapat meningkatkan hasil belajar materi pencemaran lingkungan untuk siswa kelas VII SMP Negeri Sokoria Kabupaten Ende tahun pelajaran 2019/2020.

\section{UCAPAN TERIMA KASIH}

Terima kasih kepada program studi Pendidikan Fisika dan SMP Negeri Sokoria

Ende yang memfasilitasi dan menyediakan data untuk penelitian

\section{REFERENSI}

Ariyana, Y., Bestary, R., \& Mohandas, R. (2018). Buku pegangan pembelajaran berorientasi pada keterampilan berpikir tingkat tinggi. Direktorat Jenderal Guru dan Tenaga Kependidikan Kementerian Pendidikan dan Kebudayaan.

Ary, D., Jacobs, L. C., Irvine, C. K. S., \& Walker, D. (2018). Introduction to research in education. Cengage Learning.

Calam, A., \& Qurniati, A. (2016). Merumuskan Visi dan Misi Lembaga Pendidikan. Jurnal Saintikom, 15(1), 53-68.

Ginting, E., \& Permana, Y. (2018). Modul Program Pengembangan Keprofesian Berkelanjutan melalui Pendidikan dan Pelatihan Guru moda tatap muka. Kemendikbud, 1-77.

Handriani, L. S., Harjono, A., \& Doyan, A. (2017). Pengaruh model pembelajaran inkuiri terstruktur dengan pendekatan saintifik terhadap kemampuan berpikir kritis dan hasil belajar fisika siswa. Jurnal Pendidikan Fisika dan Teknologi, 1(3), 210-220. http://dx.doi.org/10.29303/jpft.v1i3.261

KEMENDIKBUD. (2016a). Peraturan Menteri Pendidikan dan Kebudayaan Republik Indonesia Nomor 22 Tahun 2016 tentang Standar Proses Pendidikan Dasar dan Menengah. Kementerian Pendidikan dan Kebudayaan Republik Indonesia.

KEMENDIKBUD. (2016b). Lampiran Peraturan Menteri Pendidikan dan kebudayaan Nomor 24 Tahun 2016 tentang Kompetensi Dasar dan Komptensi Inti. Kementerian Pendidikan dan Kebudayaan Republik Indonesia.

KEMENKUMHAM. (2002). Undang-Undang Republik Indonesia Nomor 20 Tahun 2003 tentang Sistem Pendidikan Nasional. Jakarta: Kementerian Hukum dan Hak Asasi Manusia Republik Indonesia.

Maradila, D. A., \& Wahono, M. (2019). Implementasi Pendekatan Pembelajaran Saintifik pada Pembelajaran PPKn di Kelas X. Integralistik, 30(1), 8-16. https://doi.org/10.15294/integralistik.v30i1.18370

Musfiqon, H. M., \& Nurdyansyah. (2015). Pendekatan Pembelajaran Saintifik. Nizamia Learning Center.

National Research Council. (1996). National science education standards. National Academies Press.

Kholik, N. (2017). Peranan sekolah sebagai lembaga pengembangan pendidikan multikultural. Jurnal Tawadhu, 1(2), 244-271.

Pahrudin, A., \& Pratiwi, D. D. (2019). Pendekatan Saintifik Dalam Implementasi Kurikulum 2013 Dan Dampaknya Terhadap Kualitas Proses Dan Hasil 
Pembelajaran. Pustaka Ali Imron.

Rosana, D. (2016). Panduan Statistik Terapan Untuk Penelitian Pendidikan. Pendidikan IPA FMIPA Universitas Negeri Yogyakarta.

Sayekti, I. C. (2016). Pembelajaran IPA Menggunakan Inkuiri Terbimbing Melalui Eksperimen dan Demonstrasi Ditinjau dari Kemampuan Analisis Siswa. Jurnal Pendidikan Sains (JPS), 4(1), 6-16.

Sufairoh, S. (2017). Pendekatan Saintifik dan Model Pembelajaran K-13. Jurnal Pendidikan Profesional, 5(3). 116-125.

Sugiyono. (2007). Statistik untuk Penelitian. Alfabeta.

Suseno, H. (2016). Penerapan Model Inquiry Learning dengan Pendekatan

Saintifik Untuk Meningkatkan Keterampilan Abstrak dan Prestasi Belajar Fisika Siswa SMA. JEMS: Jurnal Edukasi Matematika dan Sains, 4(1), 43-48. http://doi.org/10.25273/jems.v4i1.209 